\title{
Mechanical characteristics of aged Hinoki wood from Japanese historical buildings
}

(short title: Mechanics of historical hinoki wood)

\author{
Misao YOKOYAMA ${ }^{* 1}$, Joseph GRIL ${ }^{1,2}$, Miyuki MATSUO ${ }^{1}$, Hiroyuki YANO ${ }^{1}$, Junji \\ SUGIYAMA $^{1}$, Bruno CLAIR ${ }^{2}$, Sigeru KUBODERA ${ }^{3}$, Takumi MISTUTANI ${ }^{3}$, Minoru \\ SAKAMOTO $^{4}$, Hiromasa OZAKI ${ }^{4}$, Mineo IMAMURA $^{4}$, Shuichi KAWAI ${ }^{1}$
}

\footnotetext{
${ }^{1}$ Research Institute for Sustainable Humanoshere, Kyoto University, Gokasho Uji-shi, Kyoto 611-0011, Japan

${ }^{2}$ Laboratoire de Mécanique et Génie Civl, Université Montpellier 2, CNRS, CC 048 Place Eugène Bataillon, 34095 Montpellier Cedex 5, France

${ }^{3}$ National Research Institute for Cultural Properties, Nara, 2-9-1 Nijyo-cho, Nara-shi, Nara 630-8577, Japan.

${ }^{4}$ National Museum of Japanese History, The National Institute for Humanities, 117-Jonai-cho, Sakura-shi, Chiba 285-8502, Japan

* Tel/Fax: +81-774-38-3634; E-mail:myokoyama@rish.kyoto-u.ac.jp
}

\begin{abstract}
Wood is present in many cultural heritage objects in Japan thanks to its capacity to resist over long period of time. However, the evolution of its properties in regular use remains insufficiently known. The present study on the effect of wood aging takes advantage of the Japanese context where building traditions have been maintained for centuries. 3-point bending tests were performed in longitudinal (L) and radial (R) directions on small clear wood specimens cut from 8 historical samples and one modern reference considered of high quality by craftsmen. Although aged wood appeared more rigid and stronger than recent wood, after density and humidity corrections were applied no significant variation of $\mathrm{L}$ and $\mathrm{R}$ rigidity or L strength was observed. The post-linear behaviour, however, was drastically influenced by wood age especially in $\mathrm{R}$ direction where the strength and rupture energy decreased markedly with the time elapsed since the wood was processed. Well-preserved aged wood can be considered as safe as long as it is not loaded perpendicular to grain.
\end{abstract}

\begin{abstract}
Le bois est present dans de nombreux objets du patrimoine en bois du Japon du fait de sa capacité à résister sur de longues durées. Toutefois, l'évolution de ses propriétés en usage demeure insuffisamment connue. La présente étude sur l'effet du vieillissement du bois tire parti du contexte japonais où les traditions constructives ont été maintenues depuis des siècles. Les essais de flexion 3 points ont été réalisés dans les directions longitudinale (L) et radiale (R) sur de petits échantillons de bois issus de 8 prélèvements historiques et d'une référence moderne considérée de la meilleure qualité par des restaurateurs. Bien que le bois âgé semble plus rigide et plus résistant que le bois récent, après correction sur la densité et l'humidité d'équilibre aucune variation significative de rigidité $L$ et $R$, ni de résistance $L$ n'est observée. Le comportement post-linéaire est par contre fortement influencé par l'âge du bois surtout
\end{abstract}


dans la direction $\mathrm{R}$ où résistance et énergie de rupture décroissent fortement avec l'âge du bois, compté depuis l'âge d'abattage estimé. Le bois âgé en bon état de conservation peut être considéré comme sûr tant qu'il n'est pas sollicité perpendiculairement aux fibres.

\section{Keywords}

Aged wood, Hinoki (Chamaecyparis obtusa), Horyu-ji temple, mechanical property, density

\section{Mots-clés}

Bois âgé, Hinoki (Chamaecydeparis obtusa), Horyu-ji, propriétés mécaniques, masse volumique

\section{Introduction}

Wood is a material designed by nature to last, provided it is not attacked by biological agents. It can support trees for centuries, and as a technological material it can again sustain loads for considerable periods. It is, as a consequence, a major component of the cultural heritage of many civilisations and the assessment of wood properties from ancient objects and structures is a question of fundamental and practical interest [1].

One major difficulty for such research is the gathering of suitable samples, with well-defined origin, certified dating and permission of publication by conservation administration. The Japanese context, where traditional uses of wood have been maintained for more than 1600 years, offers a unique opportunity to address the question of wood aging. Wood has always played a major role in Japanese culture. More than $90 \%$ of buildings listed as a National property or a nationally important cultural property of Japan are constructed with wood. The ancient capitals Kyoto and Nara have many traditional wooden buildings, some of which are listed as a World Cultural Heritage of the UNESCO. The most famous and the world's oldest wooden construction still standing is Horyu-ji temple from the latter half of the seventh century. Since 2004, a collection of wood samples from various temples and other historical building is being gathered by the Research Institute for Sustainable Humanosphere of Kyoto University (Japan), expanding a collection gathered in the 1950s by Jiro Kohara [2].

The matching of specimens from different origins is another typical obstacle. Wood is a variable material due to genetic variations and dependency on growing conditions of the trees. To discuss property changes due to aging, a recent reference is required. However, it is difficult and sometimes impossible to obtain recent wood that closely matches a given old wood sample. To overcome the difficulty, well-established structure-properties relationships can be used to produce corrections, that will allow comparing data from slightly mismatched samples.

Kohara [2] reported that the bending strength and rigidity of aged Hinoki wood, used in temple structures for over 1300 years, initially increased for a few hundred years and then decreased with increase in elapsed time. This paper presents new results obtained on similar materials. Clear wood exempt of biological attacks, effect of weathering and visible damage has been selected, so that the properties measured reflect the intrinsic aging of the material, resulting from the long-term action of moderate mechanical stress, temperature and humidity fluctuation, and air oxidation [1]. The results of mechanical testing of specimens of increasing age will be presented and discussed in relation to the possibility to predict the consequence of natural aging on wood properties. 


\section{Materials and method}

\subsection{Sample origins}

The aged samples were Hinoki (Chamaecyparis obtusa) wood from Japanese historical buildings, mostly Horyu-ji temple in Nara. It is a principle in Japan to restore historic buildings using traditional techniques and original materials. The samples are constituted not only of original material but also of replaced 'new' material from successive restorations. The specimens used in this study were cut from aged wooden members provided from the restoration sites, which were not reused. The modern wood used for comparison was taken from a 360 years old tree from Kiso region, where the highest quality Hinoki has been grown for the last 3 centuries, and selected according to craftsman viewpoint. It was cut in 1988 and had been subjected to natural drying for 19 years before testing in 2006. Samples labelling, origin and basic structural information are given in Table 1 and external views of three aged samples are displayed in Fig.1. To avoid the effect of UV degradation and insects, the outer layer parts and the nails were removed, and the specimens for mechanical testing were taken from the central portion of the samples. No sapwood occurrence was detected, so that all the studied material consisted of heartwood.

Table 1: Origin and dating of the samples

\begin{tabular}{|c|c|c|c|c|c|c|c|c|}
\hline & Collection & Origin & $\begin{array}{c}\text { Block dimensions } \\
(\mathrm{R} \times \mathrm{T} \times \mathrm{L}, \mathrm{cm})\end{array}$ & $\begin{array}{c}\mathrm{RW} \\
(\mathrm{mm})\end{array}$ & $\begin{array}{c}\text { Dendro } \\
\text { chronology* } \\
(\mathrm{AD})\end{array}$ & $\begin{array}{c}{ }^{14} \mathrm{C} \text { interval } \\
\text { dating* } \\
(\mathrm{AD})\end{array}$ & $\begin{array}{c}t_{W} \\
(\mathrm{yrs})\end{array}$ & $\begin{array}{c}t_{T} \\
(\mathrm{yrs})\end{array}$ \\
\hline \hline A & KYOw2701, RISH & HYJ & $11 \times 3.4 \times 10$ & 0.8 & $343 / 434$ & $367 / 458$ & 1618 & 1583 \\
\hline B & KYOw2738, RISH & HYJ & $7.0 \times 4.2 \times 10$ & 0.5 & $458 / 612$ & $418 / 572$ & 1467 & 1405 \\
\hline C & private & HYJ (leg) & $6.7 \times 11.5 \times 47$ & 0.9 & $400 / 502$ & $418 / 520$ & 1548 & 1515 \\
\hline D & private & HYJ (leg) & $7.5 \times 11.5 \times 55$ & 0.8 & $431 / 537$ & $421 / 527$ & 1530 & 1480 \\
\hline E & private & HYJ (leg) & $9.5 \times 13 \times 42$ & 0.7 & $584 / 792$ & $587 / 795$ & 1319 & 1225 \\
\hline F & private & HYJ (leg) & $5 \times 7.8 \times 52$ & 1.0 & $1029 / 1086$ & $1000 / 1059$ & 899 & 931 \\
\hline G & private & HYJ (leg) & $2.5 \times 14 \times 58$ & 0.8 & $1106 / 1270$ & $1098 / 1262$ & 822 & 747 \\
\hline H & (temple donation) & SJJ & $1100(\varnothing) \times 30(\mathrm{~L})$ & 0.8 & $1069 / 1438$ & $1071 / 1438$ & 753 & 569 \\
\hline I & (workshop) & Kiso forest & & 1.0 & $1622 / 1988$ & $1631 / 1973$ & 200 & 19 \\
\hline
\end{tabular}

HYJ = Horyuji temple, Nara ; (leg) = legendly ; SJJ = Senjyuji temple, Mie ; RW =average width of annual rings ; * dates (A.D.) of first/last measured growth ring; $t_{W}=$ mean time elapsed since wood formation in the measured portion; $t_{T}=$ time elapsed since tree felling (estimated upper bound for samples A to G) ; $t_{W}$ and $t_{T}$ are estimated from dendro dating.

A

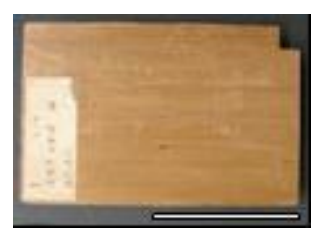

F

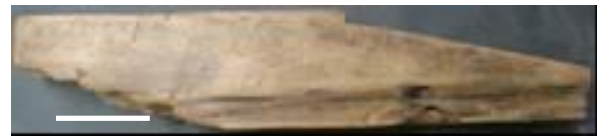


$\mathrm{H}$

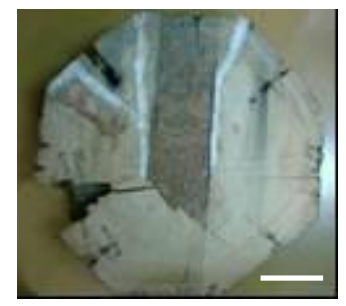

Fig. 1 External appearance of some aged samples. Scale bar $=10 \mathrm{~cm}$

A: Sample from the Dr. Jiro Kohara aged wood collection of RISH with an information of member name. It is original wood of Horyu-ji temple in Asuka era ( $7^{\text {th }}$ century).

F: Aged wood used in Horyu-ji temple legendly, without information of member and building name. It is assumed that it is used in restoration of Kamakura era, by the tool trace (an adze, chouna) of the wood surfaces and the shape of nails.

H: Aged wood from Miei-do Main hall of Senjyu-ji temple, Mie, Japan. This sample was collected in restoration site with information of precise position of the member.

It is assumed that it was transported by log raft itself from Kiso forest, by the tool trace (a chisel, nomi) and mentioned in old documents of the senjyu-ji temple (Nyoraido gokonryu-roku).

\subsection{Age determination}

To evaluate wood age, radioactive carbon chronology ${ }^{14} \mathrm{C}$ and dendrochronology were used. For each sample the wood was processed as a board containing more than 60 tree rings. Tree ring dating was performed by comparing these ring patterns with a standard pattern available until back to $912 \mathrm{BC}$ for Hinoki [3]. Distinct ring patterns of Hinoki enabled dating with yearly precision. In order to independently perform ${ }^{14} \mathrm{C}$ dating, the samples were sent to the National Museum of Japanese History, without any information of the dendro-date, and were divided into 5-yr blocks. For precision dating, ${ }^{14} \mathrm{C}$ wiggle-matching method was applied [4]. As shown in Table 1, the agreement between both methods was good: the difference between ${ }^{14} \mathrm{C}$ and dendro-date ranged from -40 to 29 years. These methods can only provide information about the wood age, defined as the time elapsed since wood formation in the tree. The analysis of colour variations in the same samples suggested that most of the aging occurred after wood processing [5], so that the period of time separating wood formation and tree felling should be subtracted from the wood age for the analysis of aging processes. However, in most cases this information is not available, and the time elapsed since tree felling $\left(\mathrm{t}_{\mathrm{T}}\right)$ cannot be calculated. For the subsequent analysis, an upper bound of $\mathrm{t}_{\mathrm{T}}$ will be considered, based on the newest visible ring on the sample. For the most recent historical sample $\mathrm{H}$ and the reference I, this gives a direct estimate as the bark was included in the sample. For the older samples the relative error is likely to be small. In the following, this estimate of $t_{T}$ will be designated as the "age" of the sample.

\subsection{Bending test}

Wood is a highly anisotropic material, much more rigid and strong along fibres (longitudinal direction, L) than across fibres (radial direction, R, or tangential, T). Although the loading of beams is dominantly applied in L direction, in the connections parts a complex stress state occurs and the response to transverse loading may become critical. For that reason, 3 points bending tests were performed not only in L, but also in $\mathrm{R}$ direction whenever enough material was available. Matched specimens of dimensions $60 \mathrm{~mm}(\mathrm{~L}) \times 10 \mathrm{~mm}(\mathrm{R}) \times 2 \mathrm{~mm}(\mathrm{~T})$ were cut for L tests, $60 \mathrm{~mm}(\mathrm{R}) \times 10 \mathrm{~mm}(\mathrm{~T}) \times 2 \mathrm{~mm}(\mathrm{~L})$ for R tests. The samples were initially dried 
at room temperature for 3 weeks in a desiccator with silica gel, and then conditioned at $20^{\circ} \mathrm{C}$ and $60 \%$ relative humidity (R.H.). They were weighed before and after the tests performed in the air-dry condition, then oven dried at $60^{\circ} \mathrm{C}, 24$ hours at atmospheric pressure and 24 hours in vacuum in presence of $\mathrm{P}_{2} \mathrm{O}_{5}$, and weighted again to calculate the moisture content during the test, as well as the oven-dry density and the air-dry density. The tests in $\mathrm{L}$ and $\mathrm{R}$ directions were performed on 5 to 10 specimens per sample and loading direction, with span length $50 \mathrm{~mm}$ and crosshead speed $5 \mathrm{~mm} / \mathrm{min}$. Equivalent stress $(\sigma)$ and strain $(\varepsilon)$ were calculated from the load $(F)$ and crosshead displacement $(f)$ as follows:

(2) $\varepsilon=6 t f / l^{2}$

where $t$ is the specimen thickness, $w$ its width, $l$ the span. These expressions correspond to the maximum value in the central part, assuming homogeneous mechanical response and linearity between stress and strain. The following parameters were used to describe each stress-strain curve: the Young's modulus or rigidity $(E)$ defined as the initial slope; the elastic limit $\left(\varepsilon^{e}\right)$ as the strain where the stress falls by $1 \%$ below the linear extrapolation from linear part; the strength $\left(\sigma^{m}\right)$ as the peak stress; the breaking strain $\left(\varepsilon^{m}\right)$ as the strain at peak stress; the rupture energy $(W)$ as the area below the curve up to the complete rupture, divided by the crosssectional area

$$
W=\frac{1}{t w} \int F \cdot d f
$$

where $F$ is the applied force and $f$ the displacement. From equations (1) and (2), $W$ can be expressed as:

$$
W=\frac{L}{9} \int \sigma \cdot d \varepsilon
$$

\subsection{Ultrastructural characterisation}

The fracture surface of some specimens was observed by a field emission scanning electron microscope (FE-SEM JSM-6700F JEOL Ltd). In order to verify the matching of the recent and aged wood, the microfibrillar angle that represents the inclination of the cellulose crystallites in the cell wall, was measured on one specimen per sample by X-Ray diffraction with a 4-circle diffractometer (Oxford Diffraction Gemini S) equipped with a 1024x1024 CCD camera. CuK_ $\alpha \square$ radiation was generated by an X-ray generator operating at $50 \mathrm{kV}, 25$ $\mathrm{mA}$. Images were integrated between $2 \theta=21.5^{\circ}$ and $23.5^{\circ}$ along the whole $360^{\circ}$ azimuthal interval to plot the intensity diagram of the (200) plane. An automatic procedure allowed the detection of the 200 peaks and their inflexion points. The T parameter as defined by Cave [6] was measured as the half distance between intersections of tangents at inflexion points with the baseline. The average microfibril angle (MFA) of each specimen was estimated by the "improved Cave's method" [7]. The results are given as the mean of values obtained for the two 200 peaks. 

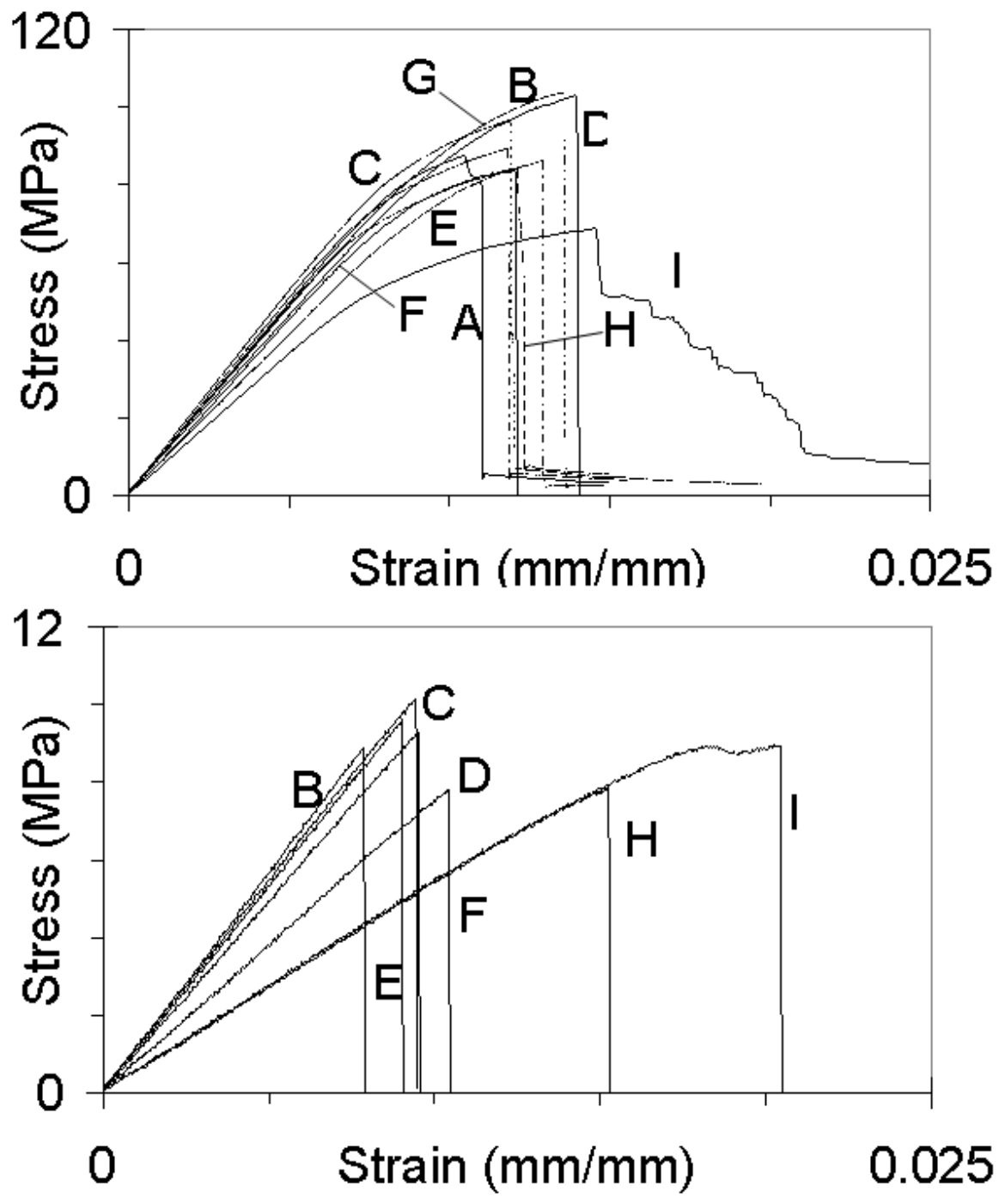

Fig. 2 Typical stress-strain curves: (a) L direction; (b) R direction

\section{Results and discussion}

\subsection{Stress-strain relationship}

Fig. 2 shows typical stress-strain curves in $\mathrm{L}$ and $\mathrm{R}$ bending for each sample. Table 2 gives physical properties, as well as, for each direction, the number of specimens mean and standard deviation for the parameters derived from the stress-strain curves. In the following, the index $\mathrm{L}$ and $\mathrm{R}$ will be used to distinguish the value for each loading direction.

Our range of air dry density, $0.33 \sim 0.49 \mathrm{~g} / \mathrm{cm}^{3}$ or of oven dry density, $0.32 \sim 0.46 \mathrm{~g} / \mathrm{cm}^{3}$, almost covers that of modern hinoki $[8,9]$. As a general trend, aged wood appeared stiffer (higher $E$ ) and stronger (higher $\sigma^{m}$ ), at least in L direction, than the modern wood tested. As will be discussed below, this can be partly explained by differences in density and moisture content. The post-linear behaviour of aged wood, on the other hand, was clearly more brittle than in modern wood: this increase in brittleness, apparent from the curves of Fig. 2, can be seen in Table 2 by the lower breaking strain $\varepsilon^{m}$ and rupture energy $W$ of aged wood, both in $\mathrm{L}$ and $\mathrm{R}$ 
direction. All aged $\mathrm{R}$ specimens exhibited a fragile response, so that the elastic limit $\varepsilon^{e}$ could only be estimated for the recent wood (sample I).

Table 2 Physical properties and mechanical properties derived from stress-strain curves.

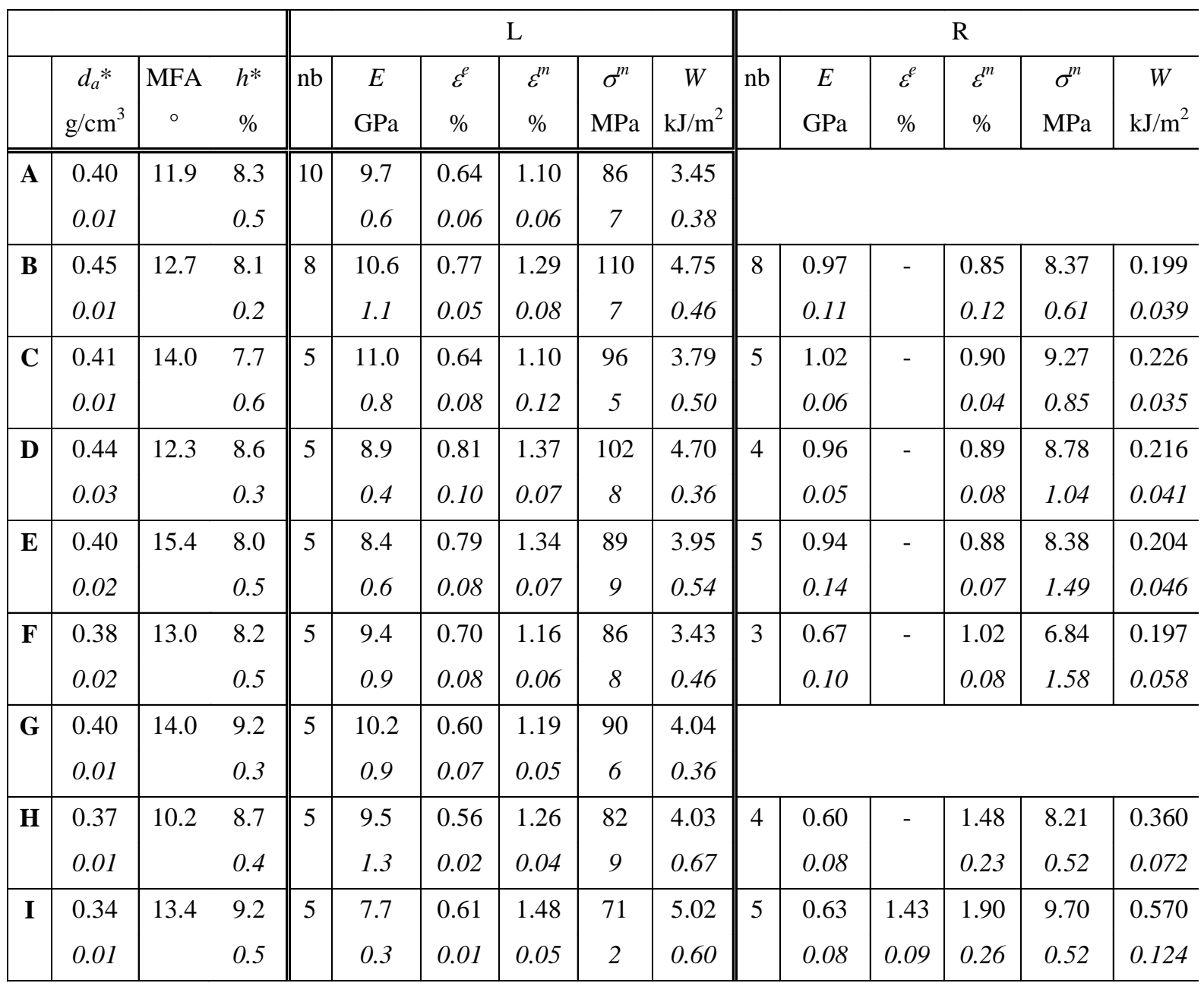

In italics: standard deviation. $d_{a}$ : air-dry density; MFA: microfibrillar angle; $h$ : moisture content; $n b$ : specimen number; $E$ : Young's modulus; $\varepsilon^{e}$ : strain at elastic limit (1\% deviation from linearity); $\varepsilon^{m}$ : strain at peak stress; $\sigma^{m}$ : strength (peak stress) ; $W$ : Energy divided by cross-section. ${ }^{*} d_{a}$ and $h$ values in this Table were calculated from L specimens.

\subsection{Corrections for sample matching}

Fig. 3 shows the relationships between sample age and air dry density $\left(d_{a}\right)$ : the older the specimens observed in our study, the denser the wood. In contrast to the density, no systematic variation of the MFA was observed: the value of the modern reference was close to the average of all aged samples, and the range of variation was small anyway. Fig.4 shows the relationships between equilibrium moisture content $(h)$ and age: $h$ tends to decrease with age according to a linear regression:

(4) $\quad h=-0.00075 t_{T}+9.2 \quad\left(\mathrm{R}^{2}=0.57\right)$

According to equation (4), 1500 years reduce $h$ by about $1.1 \%$, which is close to the decrease of $1.0 \%$ for 1200 years for the equilibrium moisture content at $60 \% \mathrm{RH}$ reported by Kohara [2]. These two effects of the age, on $d$ and $h$, bear different meanings: while $h$ decrease indicates a modification of the material properties with time, the $d$ increase reflects a possible evolution, over the centuries, of the quality of hinoki wood considered as suitable for 
structural uses. Since $h$ and $d$ influence the mechanical properties of wood, both effects need to be understood and taken into account in the analysis of the effect of elapsed time on wood properties.

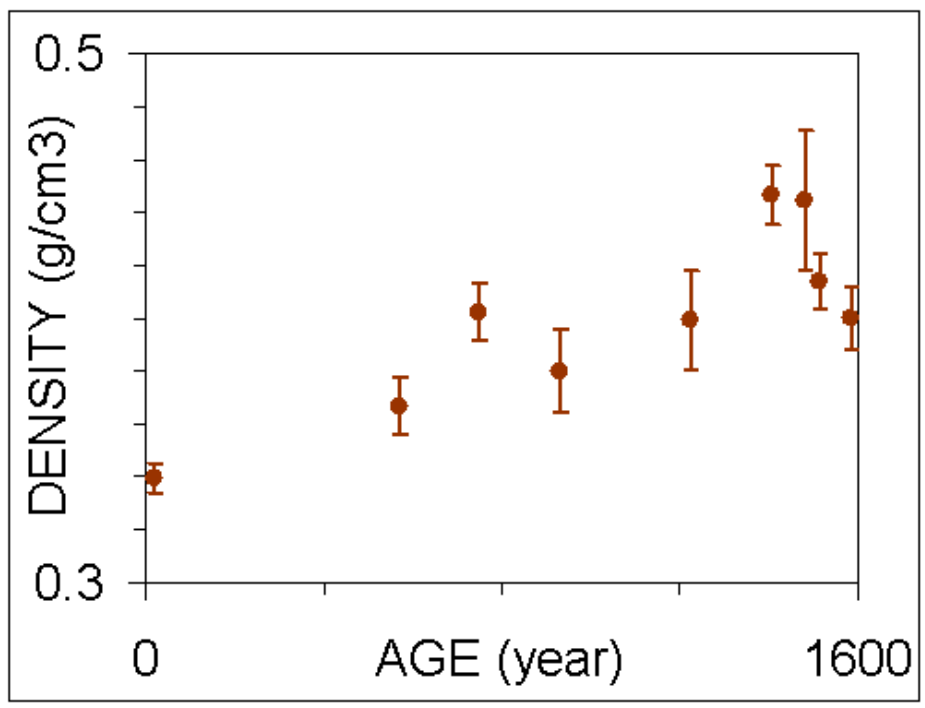

Fig 3. Relationship between age and air-dry density.

Generally speaking, quantities describing the rigidity and strength of wood tend to increase with $\mathrm{d}$ and decrease with $h$. The situation is a little more complex for the effect of $h$ on rupture energy because of the higher breaking strain in wetter wood that compensates the lower stress. The following expression can be used to describe the influence of $\mathrm{d}$ and $\mathrm{h}$ in the case of modern softwood:

$$
X(d, h)=\left(d / d_{0}\right)^{n}\left[1-\alpha \times\left(h-h_{0}\right)\right] X\left(d_{0}, h_{0}\right)
$$

where $X$ stands for Young's modulus $\left(E_{L}, E_{R}\right)$, strength $\left(\sigma^{m}{ }_{L}, \sigma^{m}{ }_{R}\right)$, fracture strain $\left(\varepsilon^{m}{ }_{L}, \varepsilon^{m}{ }_{R}\right)$ or breaking energy $\left(W_{L}, W_{R}\right)$ in $\mathrm{L}$ and $\mathrm{R}$ directions, respectively, $d_{0}$ and $h_{0}$ are reference density and humidity, respectively, and $\alpha$ and $n$ are constants depending on the type of quantity $X$. The chosen set of values for $\alpha$ and $n$ is shown in Table 3. It is taken from usual interspecies relationships for softwoods [10-14], although some authors proposed linear regression for density [11]. In L direction, the value of $n=1$ can be justified by the quasi parallel disposition of cell walls and cell cavities [10,13,15]. It can differ from 1 within a given species, when MFA and density variations are correlated. Indeed, the observed variations of $E_{L}$ and $\sigma^{m}{ }_{L}$ within modern Hinoki wood [16] could have suggested higher values of $n$ for L direction. However, based on the observation of similar MFA among the samples, the value $n=1$ seemed more appropriate in the present situation. Transversally to the fibres, the dominance of cellwall bending could increase $n$ up to the theoretical value of 3 [17], but in $\mathrm{R}$ direction due to the radial alignment of the cellular structure this level can never be reached and a range $n=1.0 \sim 1.8$ is generally observed $[10,12]$. No effect on the strain at peak stress $\left(\varepsilon^{m}{ }_{L}, \varepsilon^{m}{ }_{R}\right)$ was assumed. 


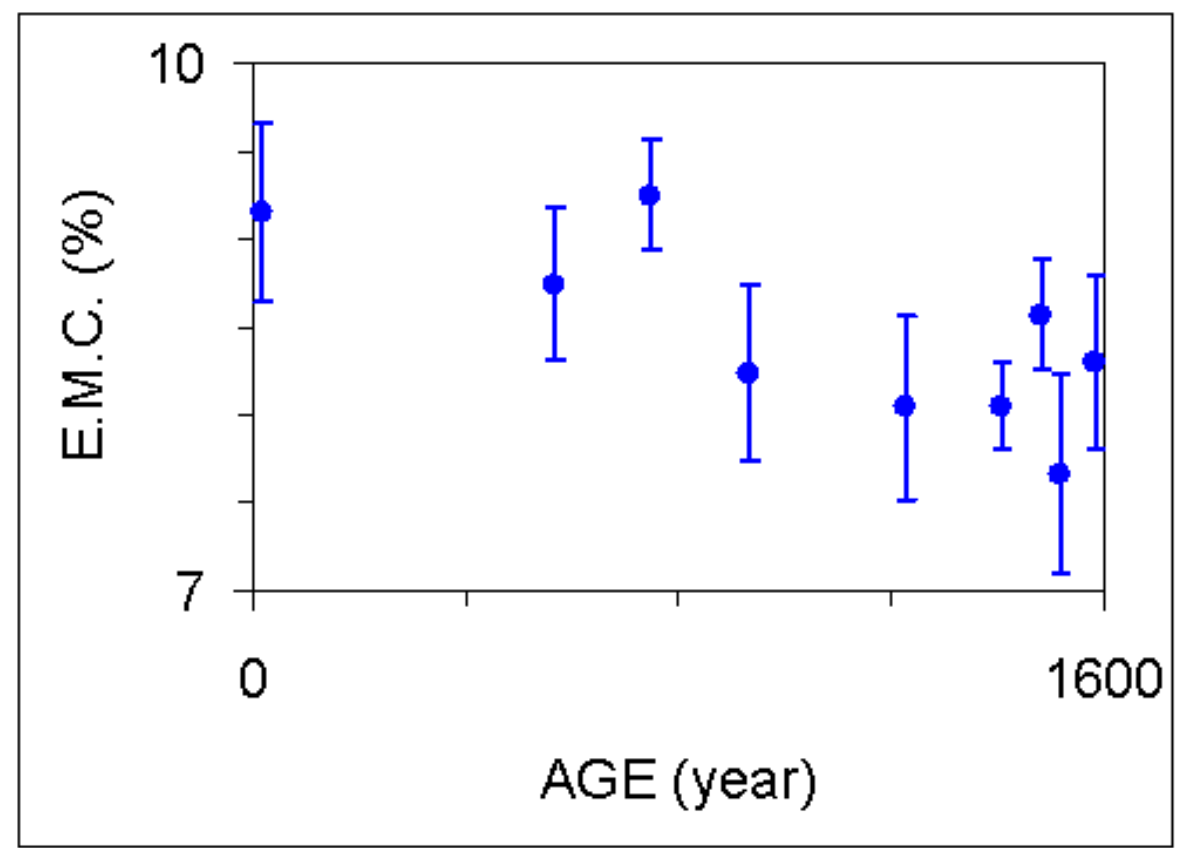

Fig. 4 Influence of specimen age on equilibrium moisture content.

Table 3 Parameters used for density and humidity corrections

\begin{tabular}{|c|cccc|cccc|} 
& \multicolumn{5}{|c|}{$\mathrm{L}$} & \multicolumn{3}{c|}{$\mathrm{R}$} \\
\hline & $\mathrm{E}$ & $\sigma^{\mathrm{m}}$ & $\varepsilon^{\mathrm{e}}, \varepsilon^{\mathrm{m}}$ & $\mathrm{W}$ & $\mathrm{E}$ & $\sigma$ & $\varepsilon^{\mathrm{m}}$ & $\mathrm{W}$ \\
\hline \hline $\mathrm{n}$ & 1 & 1 & 0 & 1 & 1.5 & 1.5 & 0 & 1.5 \\
$\alpha$ & 1.5 & 6 & 0 & 6 & 3 & 4 & 0 & 4 \\
\hline
\end{tabular}

Expression (5) can be reversed in order to produce a correction to the measured data $X(h, d)$ relative to $d_{0}$ and $h_{0}$ :

$$
X\left(d_{0}, h_{0}\right)=\frac{X(d, h)}{\left(d / d_{0}\right)^{n}\left[1-\alpha \times\left(h-h_{0}\right)\right]}
$$

Since the humidity change is itself a part of the aging process, the humidity correction may be avoided, leading to the correction:

$$
X^{\prime}\left(d_{0}, h_{0}\right)=\frac{X(d, h)}{\left(d / d_{0}\right)^{n}}
$$

The values for recent wood: $d_{0}=0.34 \mathrm{~g} / \mathrm{cm} 3$ and $h=9 \%$, will be taken as reference. The underlying viewpoint with equation (7) is that the data obtained on old wood are used to predict the long-term properties of the present material, while equation (6) highlights the property changes not merely due to the drop of moisture content. Due to the small effect of age on equilibrium moisture content, the difference between corrections (6) and (7) was small. In the next graphs, the correction according to formula both will be used.

Fig. 5a, b shows the evolution of rigidity with time. When no correction was applied, both $E_{L}$ and $E_{R}$ seemed to increase. However, after correction the trend vanishes, and both values 
fluctuate around the reference value. The same can be said for $\sigma^{m}{ }_{L}$ in Fig. 6a, but Fig. 6b shows a marked decrease of $\sigma_{R}^{m}$, especially after application of the correction. Fig. 7a shows also a clear decrease of $W_{L}$ thanks to the correction, while in Fig. $7 \mathrm{~b}$ the fall of $W_{R}$ is drastic and would have been observed even without correction. In these figures, the error bar indicates the standard deviation. In all cases, the correction resulted in a lower dispersion of the results. Fig. 8 shows the effect on strain parameters, for which no correction was tried:

the elastic limit $\left(\varepsilon^{e}\right)$ in $\mathrm{L}$ direction and the breaking strain $\left(\varepsilon^{m}\right)$ in $\mathrm{L}$ and $\mathrm{R}$ directions. A slight increase of $\varepsilon_{L}^{e}$, a slight decrease of $\varepsilon^{m}{ }_{L}$ and a drastic decrease of $\varepsilon^{m}{ }_{R}$ were observed.
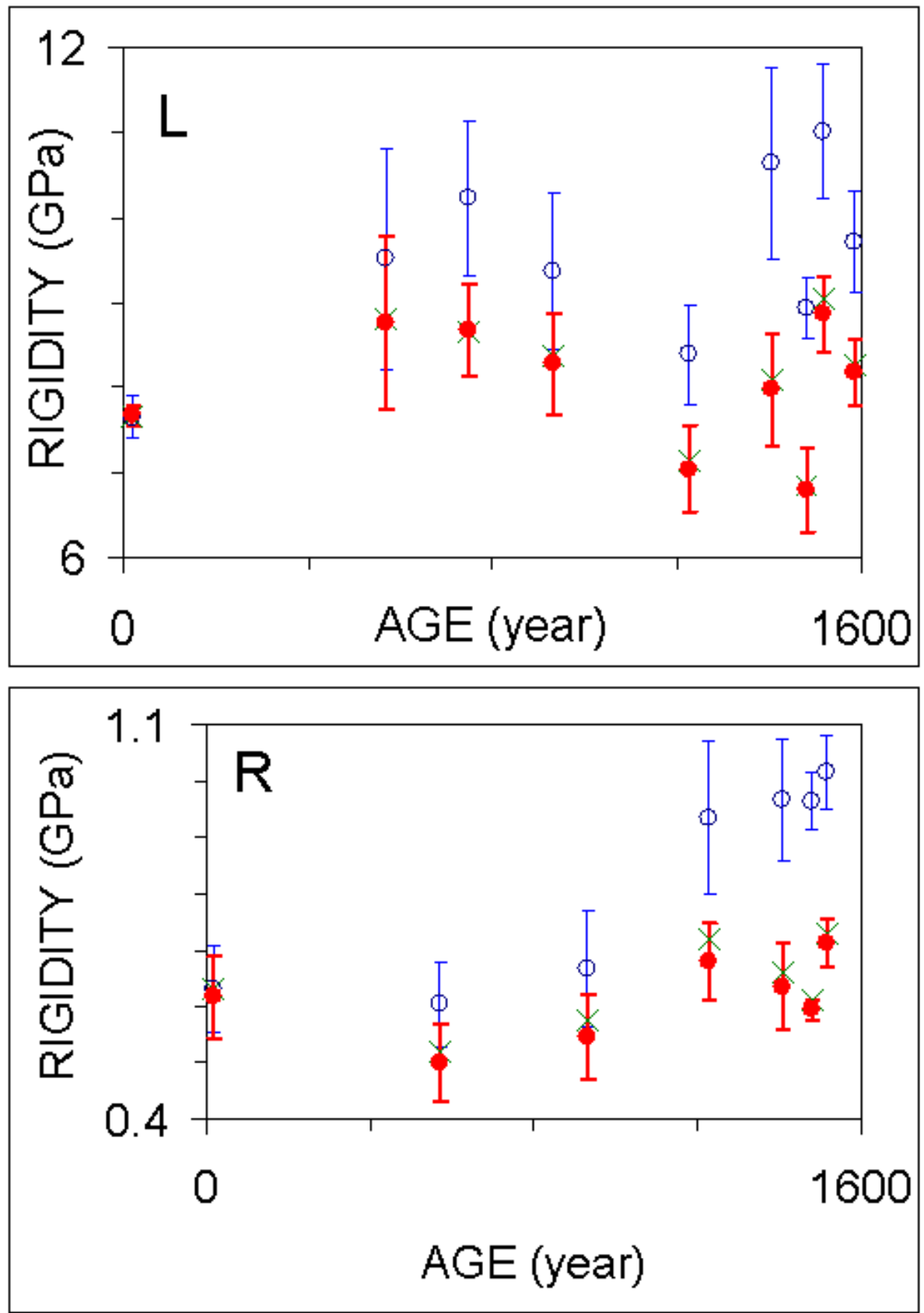

Fig. 5: Effect of specimen age on Young's modulus. Error bars indicate the standard deviation. Empty symbol and thin bars: uncorrected values; filled symbol and thick bars: corrected values ;Eq.(6);X-marks: with no m.c. correction, Eq.(7). (a) L direction, (b) R direction 

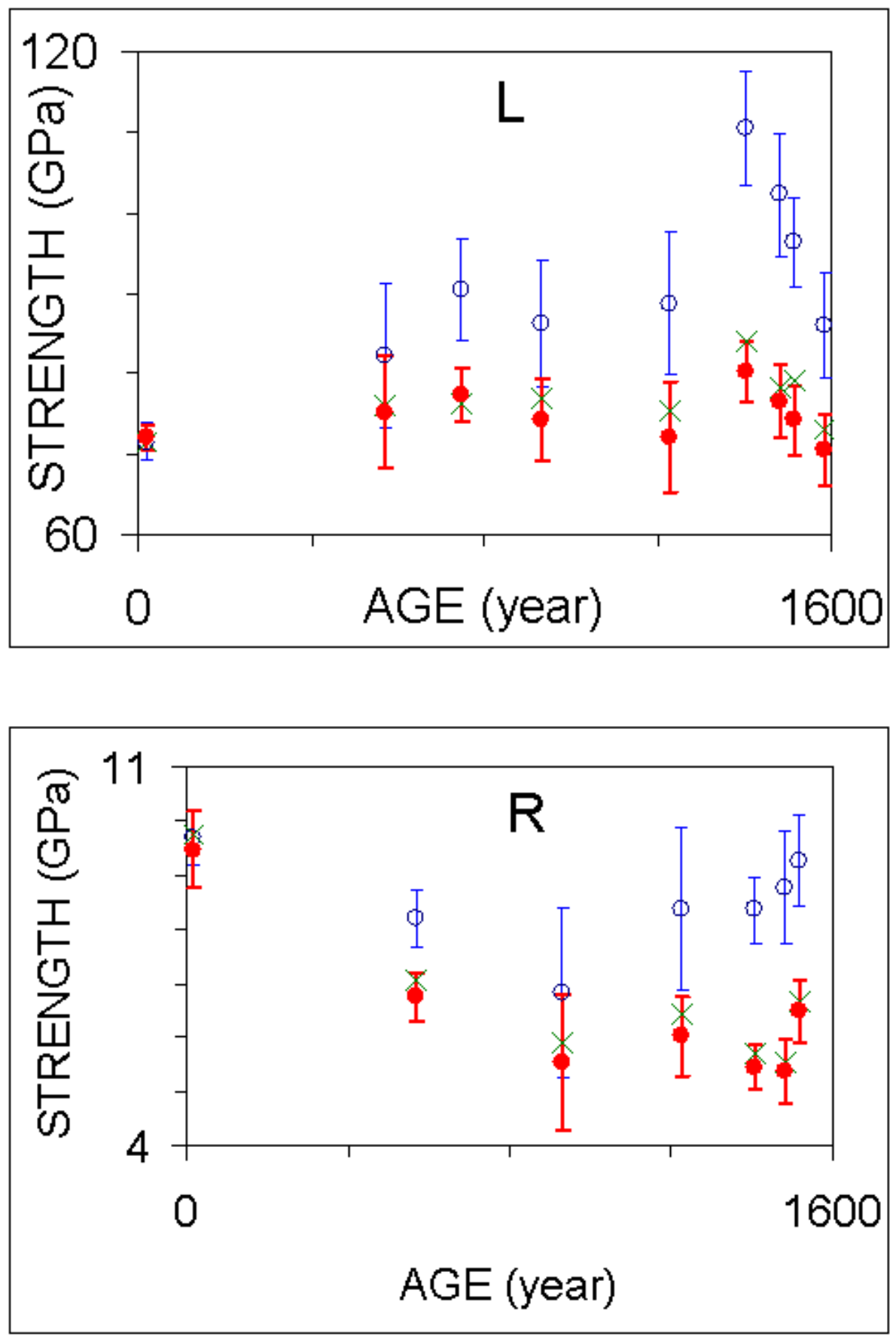

Fig. 6: Effect of specimen age on strength. Error bars indicate the standard deviation. Empty symbol and thin bars: uncorrected values; filled symbol and thick bars: corrected values ;Eq.(6);X-marks: with no m.c. correction, Eq.(7). (a) L direction, (b) R direction 

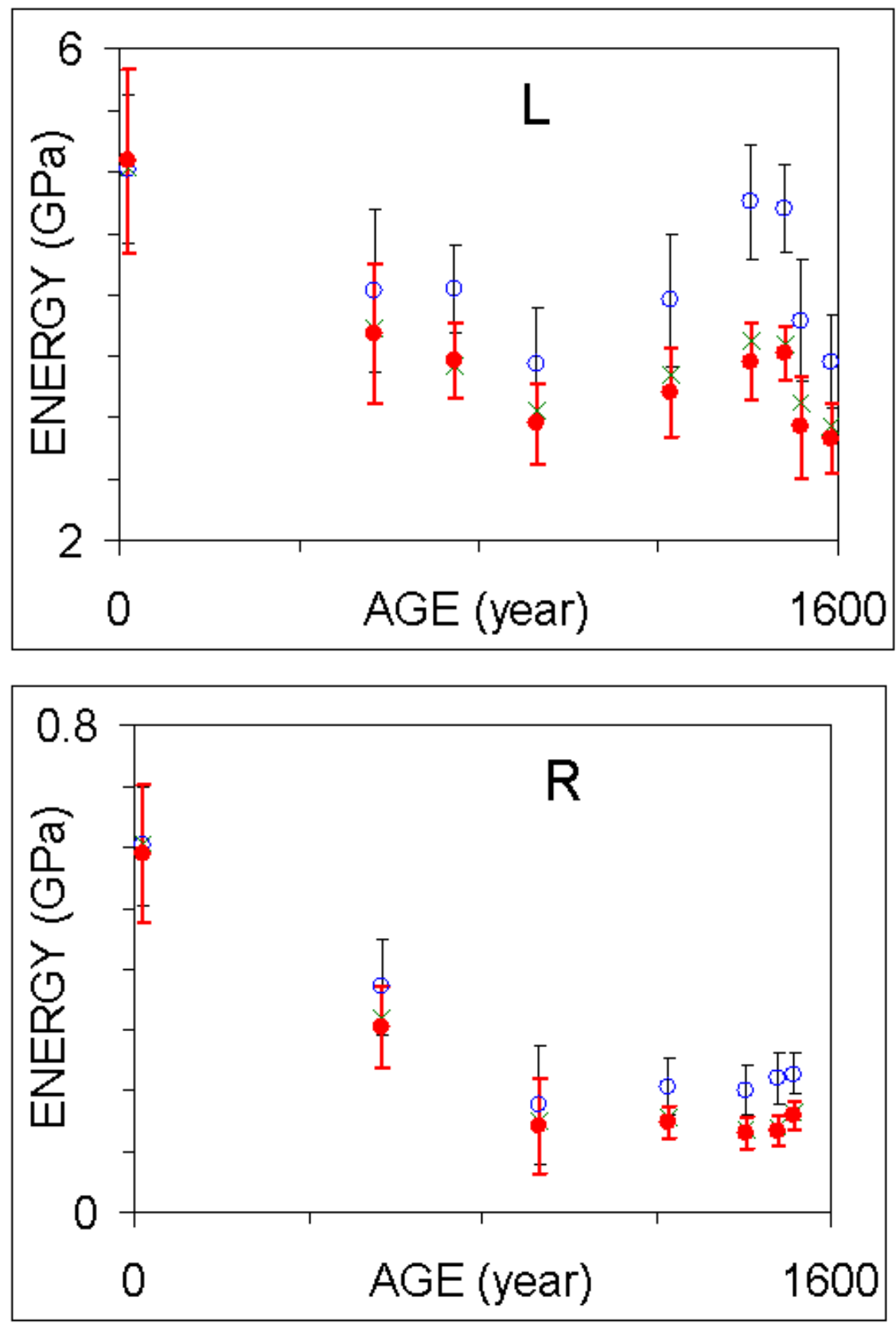

Fig.7 Effect of specimen age on rupture energy $(W)$. Error bars indicate the standard deviation. Empty symbol and thin bars: uncorrected values; filled symbol and thick bars: corrected values. ;Eq.(6);X-marks: with no m.c. correction, Eq.(7). (a) L direction, (b) R direction 


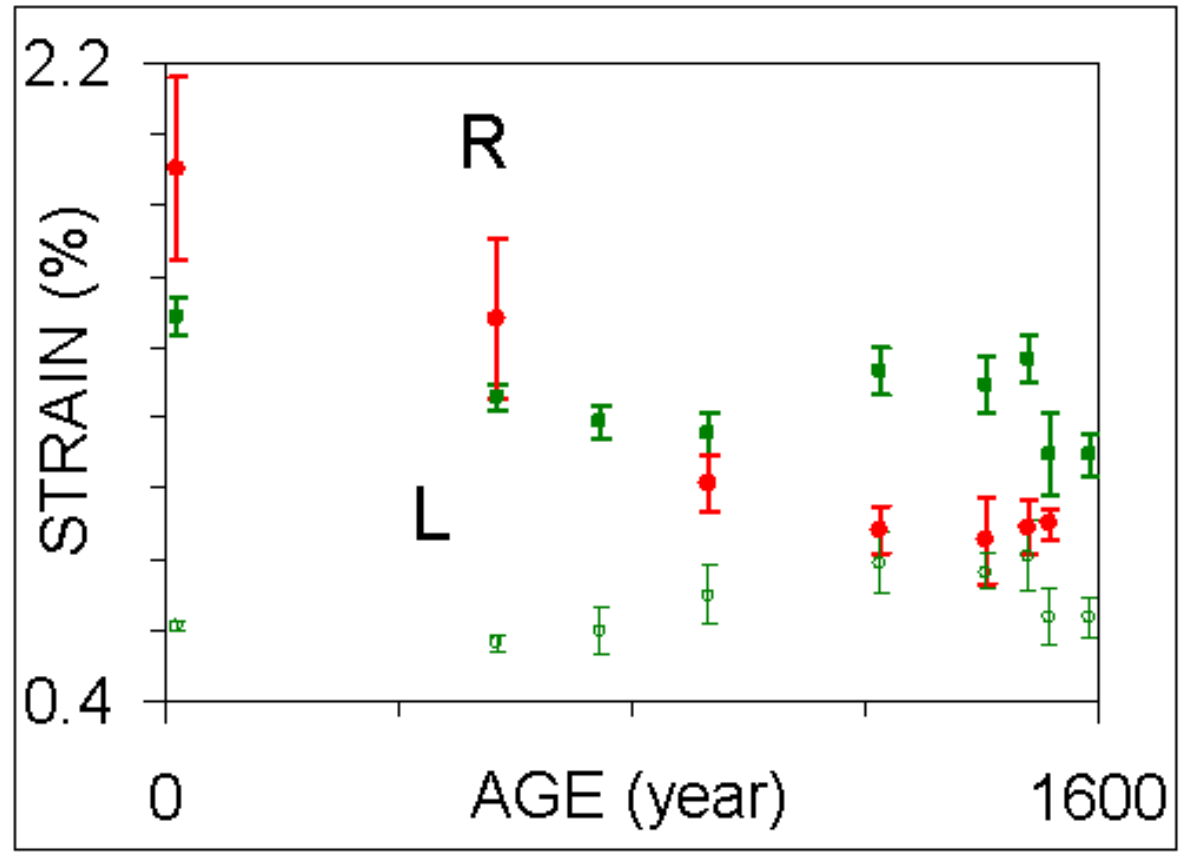

Fig. 8 Effect of specimen age on elastic limit and breaking strain. Error bars indicate the standard deviation. Cross: L direction; square R direction.

(a)

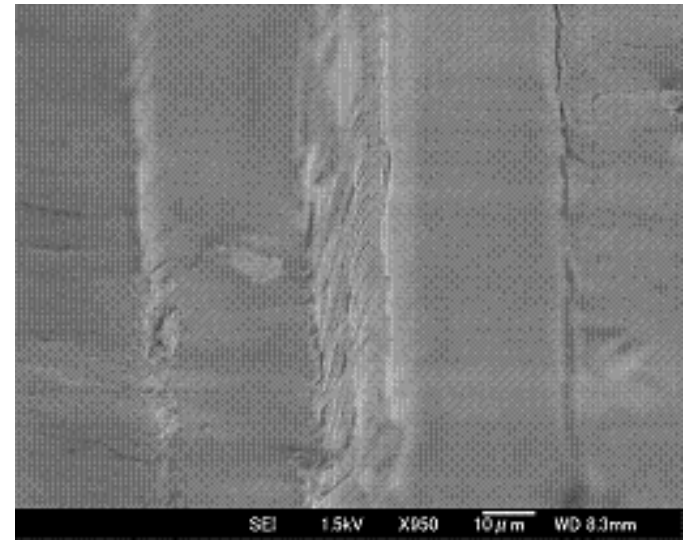

(b)

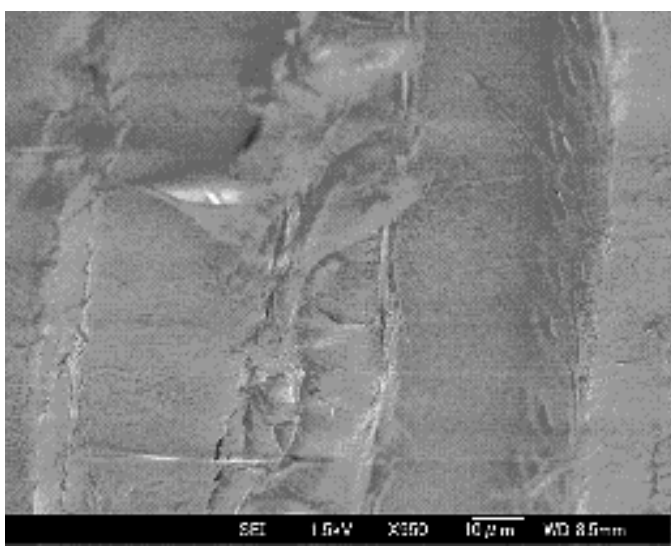

Fig. 9 Rupture face of radial specimens observed by scanning electron microscopy (a) aged wood (sample B); (b) modern wood (sample I) 


\subsection{The effect of aging on mechanical properties}

The difference of behaviour between $\mathrm{L}$ and $\mathrm{R}$ directions can be explained by the structural organisation of wood fibres. In a softwood like hinoki, most of the wood is composed of tubular tracheid cells, typically $3.5 \mathrm{~mm}$ long, $40 \mu \mathrm{m}$ diameter and with a cell-wall thickness varying between $2 \mu \mathrm{m}$ in earlywood and $4 \mu \mathrm{m}$ in latewood [18]. The cell-walls are multilayered, with a dominant $S_{2}$ layer made of axially oriented crystalline cellulose, and joined together through a strongly lignified middle lamella. There is no storied structure in hinoki; tracheids overlap randomly so that under loading in $\mathrm{L}$ direction, the stress is efficiently transferred from one cell to the next and most of the load is supported by the cell walls. Under $\mathrm{R}$ loading, a much larger proportion of the stress is supported by the middle lamella. $\mathrm{L}$ and $\mathrm{R}$ also differ at the meso-scale: the response of thin-walled tracheids in earlywood contributes dominantly under $\mathrm{R}$ load while the denser latewood bears a significant part of the L load. R rupture occurs usually by the failure of an alignment of earlywood cells, whereas in L direction a complex rupture path involving much slippage between fibres is generally observed. This explains, for the recent wood, the more developed post-linear response in L direction as compared to $\mathrm{R}$ [19].

Although aged wood-appeared more rigid and stronger than the recent wood, after density and humidity corrections no clear trend was anymore observed for $\mathrm{L}$ and $\mathrm{R}$ rigidity, as well as for L strength. The post-linear behaviour, however, was drastically influenced by wood age. Aged wood was brittle, especially in R direction where the linear elastic limit was not reached during the tests; the higher brittleness was also made evident in L direction by the decreasing distance between $\varepsilon^{m}$ and $\varepsilon^{e}$. The cellulose content and crystallinity ratio, on the other hand, do not vary significantly within modern hinoki [20] as well as between aged and modern hinoki [1]. Chemical analysis and thermomechanical testing performed in parallel to the present study evidenced a decrease of hemicellulose content [21], as well as an increase of lignin crosslinking [22]. Similar observations were previously made on other aged wood by using FTIR and NIR [23, 24]. Hemicelluloses ensure the transverse cohesion between cellulosic microfibrils and lignin matrix, so that their degradation, especially in $\mathbf{S} 2$, is also more detrimental to $\mathrm{R}$ than to $\mathrm{L}$ direction. The increase of crosslinking would increase the brittleness of lignified parts, especially in the middle lamella, thus accounting for the drastic decrease of $\mathrm{R}$ toughness without inducing any drop in rigidity. However, the lignin present in the matrix joining the microfibrils of the secondary cell wall may also be concerned. Microscopic observations of rupture faces (Fig. 9) show that the rupture under R loading does occur mainly through the middle lamella in aged wood, resulting in a smooth rupture surface. In comparison, in recent wood delamination of cell wall sublayers are observed, suggesting that the middle lamella does not break so easily. Similar observations were previously made on other softwood species [25].

Kohara observed that all these features are similar to the effect of a thermal treatment $[20,26]$. Another common effect of aging and thermal treatment is the colour change. In an another parallel study [5] dry thermal treatment in the presence of oxygen was applied to the recent and medium-aged wood, at 4 temperature levels ranging from 90 to $180^{\circ} \mathrm{C}$. Although lightness $\mathrm{L}^{*}$ systematically decreased with time or temperature, variations of redness $\mathrm{a}^{*}$ and yellowness $b^{*}$ exhibited complex patterns, indicating the combined action of several processes subject to different thermal activation. The extrapolation to the colour of ancient wood [27] was only possible by taking into account the accelerating effect of the ambient conditions, taken as equivalent to higher temperature levels. The relation of the kinetics of identified phenomena with physical and chemical changes remains to be investigated. A similar study is under progress concerning the mechanical properties. Although the general 
trends might be similar, quantitative differences are likely to be observed between the various kinds of modifications induced by age.

As a practical consequence, the results obtained suggest that ancient wood can be considered as safe as long as it is not subject to unusual action perpendicular to the grain. The existence of large wooden structures dating back more than 1200 years from now is the clearest confirmation of that statement.

\section{Acknowledgement}

The authors thank Mr. Masaji Hamashima, Mr. Mitsuo Ogawa, and the owner of the Senjyu-ji temple for obtaining samples. The research was allowed thanks to a grant by the Japanese Society for the Promotion of Science. ]

\section{References}

[1] D. Fengel, Aging and fossilisation of wood and its components, Wood Sci. Technol. 25:153-177 (1991)

[2] Kohara J, Study on the old timber, Research Report of the faculty of engineering, Chiba University 9 (15) (1958) 1-55 (in Japanese).

[3] National research Institute for Cultural properties, Dendrochronology in Japan, Nara, Bulletin 48 (1990), Dohosya press (in Japanese).

[4] M. Imamura et al., Radiocarbon wiggle - matching of Japanese historical materials with a possoble systematic age offset, Radiocarbon, vol.49, No.2 (2007) 331-337.

[5] M. Matsuo et al., Evaluation of the aging wood from historical buildings as compared with the accelerated aging wood, analysis of color properties (2009b) submitted

[6] Cave, I. D. Theory of X-ray measurement of microfibril angle in wood, Forest products journal 16(10): (1966) 37-42.

[7] H .Yamamoto et al., Method of determining the mean microfibril angle of wood over a wide range by the improved Cave's method, Mokuzai Gakkaishi 39(4): 375-381. (1993)

[8] Forestry and Forest Products Research Institute, Mokuzai Kogyou Handbook, Maruzen Press (2004) (in Japanese)

[9] H. Imamura et al, Mokuzai riyou-no kagaku, Kyoritsu Press, (1983) p38 (in Japanese)

[10] L.C.Palka, Predicting the Effect of Specific Gravity, Moisture Content, Temperature and Strain Rate on the Elastic Properties of Softwood, Wood Science technology 7(1973) 127-141.

[11] D. Guitard, Mécanique du matériau bois et composites. Toulouse, France, CépaduèsEditions (1987)

[12] C.C.Gerhards, Effect of Moisture Content and Temperature on the Mechanical Properties of Wood: An analysis of Immediate Effects, Wood and Fiber, 14(1)(1982) 4-36.

[13] T.Yamada, Studies on Rheological Properties of Wood and Structure of cell wall, and Mokuzai Gakkaishi 17 (2) (1971) 36-43.(in Japanese)

[14] S. Kajita et al., Studies on Rheological Properties of Wood II- Effect of Heat Treating Condition on the Hygroscopicity and Dynamic Young's Modulus of Wood,Mokuzai Gakkaishi (1962) 29-33.(in Japanese) 
[15] M. Norimoto et al., Young's modulus of cell wall in soft wood, Nihon Reology Gakkaishi 9(4), (1981)169-175. ( in Japanese)

[16] E.Sano, On the Mechanical Properties of Japanese Hinoki-wood, Mokuzai Gakkaishi vol.8 No.1(1962) 7-12 (in Japanese)

[17] Gibson L.J., Ashby M.F. Cellular solids, structure and properties, Cambridge University Press, (1997)

[18] K.Shimaji et al, Wood Structure, Buneido Press(1985) p29(in Japanese)

[19] L. Salmen, I. Burgert, Cell wall features with regard to mechanical performance. A review COST Action E35 2004-2008: Wood machining - micromechanics and fracture, Holzforschung. 63 (2), (2009) 121-129,

[20] J.Kohara, H.Okamoto, Study on the old timber - Changes in chemical component, Mokuzai Gakkaishi 2(5) (1956) 191-195

[21] W.Ragil et.al. Evaluation of aged wood from historical Japanese buildings II Changes in Chemical component, Proceedings of the $57^{\text {th }}$ Annual meeting of the Japanese Wood Research Society (2007)

[22] M. Yokoyama et al. Evaluation of aged wood from historical Japanese buildings IChanges in Mechanical properties of Hinoki wood, Proceedings of the $57^{\text {th }}$ Annual meeting of the Japanese Wood Research Society (2007)

[23] T.Takei et al., Fourier Transform Infrad Spectroscopic Analysis of the Degradation of Structural Lumber in Horyu-ji Temple, Mokuzai Gakkaishi 43(3) (1997) 285-294(in Japanese)

[24] H.Yonenobu, S.Tsuchikawa, Near-Infrared Specdtroscopic Comparison of Antique and Modern Wood, Applied Spectroscopy 57(11) (2008) 1451-1453

[25] K. Bordin et al., The effect of Aging on the Ultrastructure of wood, Wood Science and Technology 9 (1975) 87-98

[26] J.Kohara, H.Okamoto, Study on the old timber - Increasement in Young's modulus of heat-treated wood, Mokuzai Gakkaishi 1(2) (1955) 80-84 (in Japanese)

[27] M. Matsuo et al., Color changes in wood during heating: Kinetic analysis by applying time-temperature superposition method (2009a) submitted 